\title{
Hyponatraemia, harm reduction and the O'Hara report from Northern Ireland
}

\author{
William P. Tormey ${ }^{1,2,3,4}$
}

Received: 25 November 2019 / Accepted: 25 November 2019 /Published online: 9 December 2019

(C) Royal Academy of Medicine in Ireland 2019

The report on the 'Inquiry into hyponatraemia-related deaths' under the chairmanship of John O'Hara QC is an important anchor for the issue of teaching, assessment and practice in the field of electrolyte management [1]. The report outlined the systematic pathway instituted in Northern Ireland to improve fluid prescription in paediatrics. In parallel, the National Institute for Health and Care Excellence (NICE) published clinical guideline NG29 on the subject of 'intravenous fluid therapy for children and young people in hospital' [2]. This guideline directs at least hourly measurements of plasma sodium and intervention that restricts the change in sodium to $<12 \mathrm{mmol} / \mathrm{L}$ in $24 \mathrm{~h}$. In NG29, there is no reference to reference change value of sodium which in Beaumont hospital Dublin is $3.209 \%$. At a sodium value of $121 \mathrm{mmol} / \mathrm{L}$, two SDs either side of the mean delineates the $95 \%$ confidence interval and this is 118.78 to $123.5 \mathrm{mmol} / \mathrm{L}$. This means that changes within these parameters may be random. Therefore over-interpretation of sodium values measured hourly is likely [3]. As laboratories will have different analytical equipment, the reference change value (RCV) for sodium can be calculated when the analytical precision is measured and known. An RCV for sodium in a paediatric population has been published with details of the biological variation included. That RCV value was $2.40 \%$. The same paper listed an adult RCV for sodium of $2.90 \%$ [4]. The figure, which should be calculated locally, will have clear implications for treatment.

William P. Tormey

billtormey@gmail.com

1 Biomedical Science, Ulster University, Cromore Road, Coleraine, Ireland

2 Beaumont Hospital, Dublin 9, Republic of Ireland

3 Trinity College Medical School, Dublin 2, Ireland

4 Irish Journal of Medical Science, Royal Academy of Medicine, RCPI Kildare Street., Dublin 2, Ireland
On page 30 of the NG29, it is noted that that in the UK 'there is little formal training and education in IV fluid management to support correct prescribing'. A questionnaire completed by 286 Foundation Year One (FY1) doctors in 2018 reported that $52.44 \%$ regarded their undergraduate teaching as 'neither poor nor good', 'poor' or 'very poor'. Two hundred thirty-four of these attended one of 19 medical schools in Britain. $7 \%$ of FY1 doctors reported being the principal fluid prescribers on their clinical teams and in only $6 \%$ of teams did the consultant share the responsibility [5]. Staff training in the competent use of near patient testing devices is an often ignored component of safe practice and should form part of the annual competence evaluation by the GMC.

The chairman observed in paragraph 8.16 that "there can be no room for complacency because total patient safety cannot be assured." He recommended that “children's wards should have a senior lead nurse to provide the active leadership necessary to reinforce nursing standards and to audit and enforce compliance with guidance". This recommendation is inadequate because the topic requires round the clock expertise. In paragraph 8.17 , a truism is stated that 'competency in fluid management is reliant upon training'. This brings into focus who does the undergraduate teaching in both medicine and nursing and later who ensures the postgraduate training is sufficient and effective. The deficit of focus on paediatric prescribing training of foundation doctors in Belfast is referred to in paragraph 8.18 of the O'Hara report.

The use of the laboratory as a robust vehicle for the identification of dangerous levels of hyponatraemia is not identified in the report. The Royal College of Pathologists lists a threshold plasma sodium of $130 \mathrm{mmol} / \mathrm{L}$ for under 16 years old as a critical threshold value for communication to the clinician. A comment lists concern for the risk of death in children with hyponatraemia [6]. Furthermore, laboratory accreditation to the ISO15189 standard requires the laboratory to have robust standard operating procedures to inform clinicians when results of analyses fall outside critical limits. Thus all patients in hospital with potentially dangerous plasma sodium 
values should be identified within standard laboratory turnaround times. This service is rigorously inspected repeatedly. Inspection for accreditation of clinical laboratories in the Republic of Ireland to ISO15189 standard is supervised by the Irish National Accreditation Board [7]. Certification is for 5 years with annual on-site reconfirmation surveillance visits. The accreditation agencies serving Belfast include UKAS and the Medicines and Health Care Products Regulatory Agency (MHRA) [8]. UKAS operates to the ISO15189 standard $[9,10]$. The use of Point-of-Care instruments for blood gases and electrolytes is now commonplace in hospitals especially in Accident and Emergency departments, theatres and intensive care areas. Regulation is by ISO22870 which requires individual training and competency assessments of all users. This standard must accompany ISO15189 within the overall clinical laboratory template. Other than for blood transfusion and organ transplant services, clinical laboratory accreditation is not mandatory by law. This should be changed.

Annual on-line re-affirmation of knowledge of electrolytes and their clinical management for all prescribing clinical staff must be a baseline to prevent recurrence of hyponatraemia misadventures. This will likely improve clinical teaching in the first instance.

Thus, the O'Hara report is not comprehensive. Risk reduction must be driven by the implementation of best practice by the General Medical Council and national accreditation bodies in the interests of all patients.

\section{References}

1. The inquiry into hyponatraemia-related deaths. Report January 2018. www.ihrdni.org/inquiry-report.htm. Accessed 7 Feb 2019

2. (2015) Intravenous fluid therapy in children and young people in hospital. https://www.nice.org.uk/guidance/ng29. Accessed 15 July 2019

3. Tormey, Carney M, Cuesta M, Sreenan S (2015) Reference change values for sodium are ignored by the American and European treatment guidelines for hyponatremia. Clin Chem 61(12):1430-1432. https://doi.org/10.1373/clinchem.2015.242602

4. Bailey D, Bevilacqua V, Colantonio DA, Pasic MD, Perumal N, Khun Chan M, Adeli K (2014) Pediatric within-day biological variation and quality specifications for 38 biochemical markers in the CALIPER cohort. Clin Chem 60(3):518-529. https://doi.org/10. 1373/clinchem.2013.214312

5. Lupi MM, Maweni RM, Shirazi S, Wali UJ (2019) Fluid and electrolyte balance-establishing the knowledge base of foundation year one doctors. Ir J Med Sci 188(3):1047-1055. https://doi.org/10. 1007/s11845-018-1937-4

6. Croal B (2017) The communication of critical and unexpected pathology results. The Royal College of Pathologists

7. https://www.rcpath.org/uploads/assets/bb86b370-1545-4c5ab5826a2c431934f5/the-communication-of-critical-andunexpected-pathology-results.pdf. Accessed 16 July 2019

8. Irish National Accreditation Board. Medical testing. inab.ie. Accessed 16 July, 2019

9. Northern health and social care trust; Laboratory handbook, clinical pathology laboratory. A users guide to laboratory services. northerntrust.hscni.net. Accessed 16 July 2019

10. https://www.ukas.com/services/accreditation-services/medicallaboratory-accreditation-iso-15189/. Accessed 16 July 2019

Publisher's note Springer Nature remains neutral with regard to jurisdictional claims in published maps and institutional affiliations. 